\title{
High Night Temperatures Do Not Cause Poor Lateral Branching of Chrysanthemum
}

\author{
James E. Faust ${ }^{1}$ and Royal D. Heins ${ }^{2}$ \\ Department of Horticulture, Michigan State University, East Lansing, \\ MI 48824-1325
}

Additional index words. axillary bud, Dendranthema $\times$ grandiflorum, lateral shoot

\begin{abstract}
Dendranthema xgrandiflorm (Ramat.) Kitamura 'Powerhouse' plants were pinched to five nodes and grown in growth chambers at 35C day temperature (DT) and $14,17,21,24$, or $27 \mathrm{C}$ night temperature (NT) to determine if NT influenced lateral shoot development on plants exposed to high DT. Vegetative cuttings were removed from two successive flushes of lateral shoots and evaluated for lateral shoot development after rooting and subsequent apex removal. Lateral shoot development was determined on a third flush of shoots that developed on the stock plants. The percentage of nodes that developed lateral shoots on stock plants or vegetative cuttings was not related to NT. The percentage of first-order, second-order, and third-order axillary nodes that developed a lateral shoot on the stock plants, averaged over all NT, was 76, 65, and 12 , respectively. The percentage of nodes that developed lateral shoots on the firstorder and second-order cuttings was 29 and 19, respectively. We concluded that cool NT were ineffective in preventing a decrease in lateral branching on plants grown under high (35C) DT conditions.
\end{abstract}

Successful commercial production of flowering, container-grown plants often depends on the development of axillary buds after stem apex removal (pinching). In chrysanthemun production, vegetative cuttings

Received for publication 18 Oct. 1991. Accepted for publication 3 Apr. 1992. We acknowledge the support of the Michigan Agricultural Experiment Station and Yoder Brothers, Inc., Barberton, Ohio. The cost of publishing this paper was defrayed in part by the payment of page charges. Under postal regulations, this paper therefore must be hereby marked advertisement solely to indicate this fact. 'Graduate Research Assistant.

${ }^{2}$ Professor of Horticulture. harvested from stock plants are rooted and pinched so that five to eight nodes remain to produce lateral shoots (Crater, 1980; Hanzel, 1989). Plants with an insufficient number of lateral shoots are not marketable.

Most chrysanthemum cuttings produced in the United States originate from stock plants grown in Florida and California. The cuttings are harvested from field-grown plants and shipped to growers for forcing. Some cultivars (e.g., 'Powerhouse') grown during the summer near Fort Myers, Fla., have many nodes that do not develop lateral shoots after pinching (C. Scharfenberg, personal communication). Failure to branch is related to incomplete axillary bud development. Nor- mally branched plants are produced when cuttings are harvested from these cultivars during the winter near Fort Myers or during summer and winter near Salinas, Calif. The major environmental difference between seasons and the two locations is temperature. The daily mean minima and maxima during January are 20/27C near Fort Myers (M Hackmann, personal communication) and 4/ $16 \mathrm{C}$ in Salinas (U.S. Dept. of Commerce, 1960); during July, they are $22 / 34 \mathrm{C}$ and $17 /$ $22 \mathrm{C}$, respectively. High temperatures, during either the day, night, or both, were therefore hypothesized to be the cause of the poor lateral-shoot development on summer-grown cuttings produced in Florida.

The objective of this experiment was to determine the effect of night temperature (NT) on lateral-shoot development of chrysanthemums grown at high day temperature (DT).

Rooted cuttings received from Salinas were potted in $1271-\mathrm{cm}^{3}$ pots and placed in growth chambers set at 25C DT and 20C NT. After 1 week, the plants were pinched to five nodes. Cuttings were selected that possessed an axillary bud at each node. Twenty-five plants were placed into each of five growth chambers with NT of 14 , $17,21,24$, or $27 \mathrm{C}$. DT was programmed to increase from 27 to $35 \mathrm{C}$ during the first $4 \mathrm{~h}$ of the photoperiod, to remain at $35 \mathrm{C}$ for $8 \mathrm{~h}$, and to decrease to $27 \mathrm{C}$ during the last $4 \mathrm{~h}$ of the photoperiod. The photosynthetic photon flux density at canopy height was maintained at 600 to $700 \mu \mathrm{mol} \cdot \mathrm{m}^{-2} \cdot \mathrm{s}^{-1}$ from cool-white fluorescent lamps for 16 $\mathrm{h} \cdot \mathrm{day}^{-1}\left(35\right.$ to $\left.40 \mathrm{~mol} \cdot \mathrm{m}^{-2} \cdot \mathrm{day}^{-1}\right)$.

Lateral shoots developed from the firstorder axillary buds and cuttings were taken 27 days after pinching (Fig. 1). A cutting 5 to $7 \mathrm{~cm}$ long with about seven unfolded leaves was taken from each lateral shoot, and two nodes were left on each of the stock plants' lateral shoots. These cuttings were sent overnight to Yoder Brothers, Inc., Alva, Fla., 

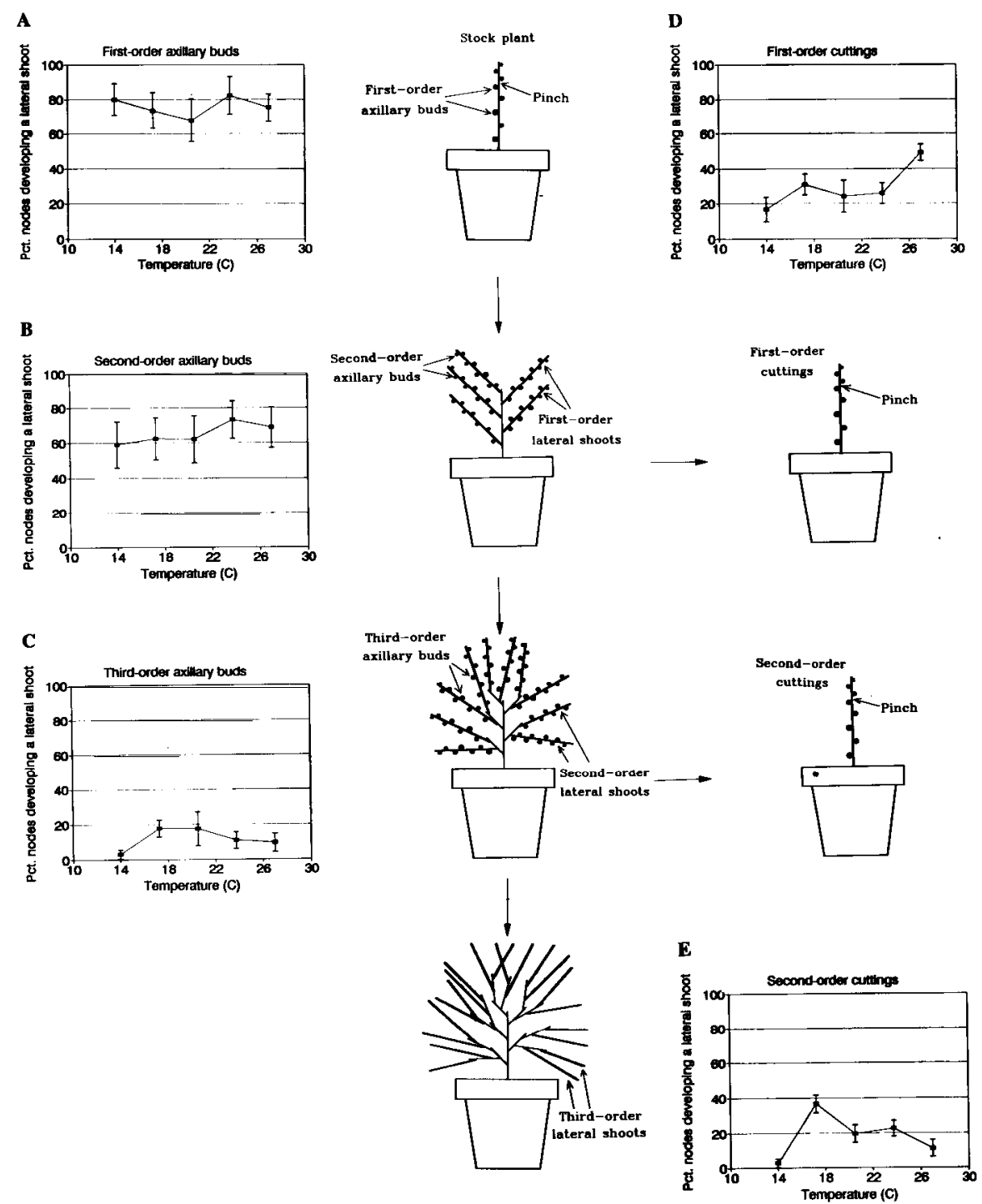

Fig. 1. Scheme for axillary bud development, lateral-shoot development, and cutting production from a chrysanthemum stock plant. Graphs display the effect of night temperatures on the percentage of lateral shoots developing from the indicated axillary buds. (A) Fist-order, (B) second-order, and (C) third-order lateral buds developing on the stock plant. First-order lateral buds developing from (D) the first-order and (E) the second-order cutting. Vertical bars represent $95 \%$ confidence limits.

where they were propagated, pinched, and evaluated for lateral shoot development.

Lateral shoots developed from the secondorder lateral buds remaining on the stock plants, and second-order cuttings were taken 21 days after the first-order cuttings were removed. Two nodes containing the thirdorder lateral buds were left on each secondary lateral shoot of the stock plant after cutting removal. The second-order cuttings also were sent to Yoder Brothers. After the second-order cuttings were taken, the stock plants were moved to a greenhouse maintained at 21C. The number of lateral shoots that developed from third-order axillary buds on the stock plants was recorded 28 days later.

NT had no significant effect on the per-

illary buds that developed lateral shoots (Fig. 1A-C). The average percentage of first-, second-, and third-order axillary buds that developed into lateral shoots over all NT was $76 \%, 65 \%$, and $12 \%$, respectively. Visual observations indicated that the lack of lateral shoot development was not due to inhibition of axillary bud growth but to incomplete differentiation of the lateral buds, i.e., leaf axils were devoid of buds.

Both cutting order and NT affected the percentage of shoots that developed (Fig. 1 $\mathrm{D}$ and E). After cuttings were rooted and pinched, an average of $29 \%$ and $19 \%$ of the axillary buds developed a shoot on the firstand second-order cuttings, respectively. NT treatments had a statistically significant, but inconsistent, effect on the percentage of nodes that formed lateral shoots.

Assuming axillary bud development in chrysanthemum is similar to the bud development in some other species (Garrison, 1949; Sussex, 1955), the first- and second-order axillary buds in the first-order lateral shoots and first leaves, respectively, should have been initiated before the start of the experiment. However, most of the nodes on the first-order cuttings, all of the nodes on the second-order cuttings, and all of the thirdorder axillary buds on the stock plant were initiated during our experiments. The percentage of axillary buds that formed a lateral shoot on the first- and second-order cuttings was very low, as were third-order axillary buds on the stock plant. The result was a trend toward a lower percentage of lateral shoots developing over the time of the experiment. The results suggest that the treatments inhibited axillary bud initiation but did not affect the lateral-shoot growth of preexisting axillary buds. We hypothesize that the relatively high percentage of first- and second-order lateral shoots that developed on the stock plants was a result of axillary bud presence before the start of the experiment.

Lateral branching on the experimental stock plants and cuttings became progressively poorer from one generation to the next under all NT treatments, while nodes of the cultivar Powerhouse typically produce a high percentage of lateral shoots when grown commercially under a moderate-temperature environment. These facts suggest that high DT alone was capable of causing poor lateral branching in chrysanthemum. The environmental conditions used in this experiment successfully reproduced the poor-branching phenomenon found in 'Powerhouse'; however, lower NT did not ameliorate the problem. We conclude that environmental conditions other than high NT are responsible for poor lateral-shoot development in chrysanthemum. High DT, either directly or indirectly, is the probable cause. The specific environmental conditions that inhibit differentiation of axillary meristems must still be determined.

\section{Literature Cited}

Crater, D.G. 1980. Pot mums, p. 263-287. In: R.A. Larson (ed.). Introduction to floriculture. Academic, New York.

Garrison, R. 1949. Origin and development of axillary buds: Betula papyrifera Marsh. and Euptelea polyandra Sieb. et Zucc. Amer. J. Bot. 36:379-389.

Sussex, I.M. 1955. Morphogenesis in Solanum tuberosum L.: Apical structure and developmental pattern of the juvenile shoot. Phytomorphology 5:253-273.

U.S. Department of Commerce. 1960. Local climatological data: Annual summary. U.S. Dept. of Commerce, Natl. Oceanic and Atmospheric Admin., Environ. Data Serv., Natl. Climate Data Ctr. 